\title{
Biomechanical effect of intertrochanteric curved varus osteotomy on stress reduction in femoral head osteonecrosis: a finite element analysis
}

\author{
Yuzhu Wang ${ }^{1}$, Go Yamako ${ }^{2 *}$, Takato Okada ${ }^{3}$, Hideki Arakawa ${ }^{1}$, Yoshihiro Nakamura ${ }^{1}$ and Etsuo Chosa ${ }^{1}$
}

\begin{abstract}
Background: Intertrochanteric curved varus osteotomy (CVO) has been widely used to remove the necrotic bone away from the weight-bearing portion in the treatment of osteonecrosis of the femoral head (ONFH). However, whether all types of necrosis will benefit from CVO, in terms of the stress level, the effect of different center-edge (CE) angles of acetabulum on stress distribution of necrosis after CVO, and the relationship between the intact ratio and the stress of necrosis, has never been addressed. The purpose of the study was to evaluate the influence of CVO on the stress reduction in necrotic bone using a finite element analysis (FEA) with different CE angles.

Methods: CVO finite element models of the hip joint were simulated with a lesion of $60^{\circ}$. The osteotomy angles were divided into four configurations $\left(15^{\circ}, 20^{\circ}, 25^{\circ}\right.$, and $\left.30^{\circ}\right)$, and three types $(A, B$, and $\mathrm{C} 1$ ) of lesions were established based on the Japanese Investigation Committee (JIC) classification. In addition, two CE angles ( $18^{\circ}$ and $33^{\circ}$ ) of acetabulum were considered. The maximum and mean von Mises stress were analyzed in terms of the necrotic bone by a physiological loading condition. Moreover, the correlation of the intact ratio measured in 3D and the stress distribution after CVO was analyzed.

Results: Stress reduction was obtained after CVO. For type B, the CVO angle was $20^{\circ}(0.61 \mathrm{MPa})$, and for type C1, the CVO angle was $30^{\circ}(0.77 \mathrm{MPa})$, if the mean stress level was close to type $\mathrm{A}(0.61 \mathrm{MPa})$, as a standard. The maximum and mean von Mises stress were higher in the CE angle of $18^{\circ}$ models, respectively. The intact ratio measured in 3D had a good negative correlation with stress after CVO and had more influence on stress distribution in comparison to other geometric parameters.

Conclusions: For making decisions about the biomechanics of $\mathrm{CVO}$, a $\mathrm{CVO}$ angle of $>20^{\circ}$ was recommended for type $\mathrm{B}$ and $>30^{\circ}$ was safe for type $\mathrm{C}$. The risk of progressive collapse was increased in the insufficient situation of the weight-bearing portion after CVO. The intact ratio could provide information about clinical outcomes and stress distribution after CVO.
\end{abstract}

\footnotetext{
* Correspondence: g.yamako@cc.miyazaki-u.ac.jp

${ }^{2}$ Department of Mechanical Engineering, Faculty of Engineering, University of Miyazaki, Miyazaki, Miyazaki, Japan

Full list of author information is available at the end of the article
}

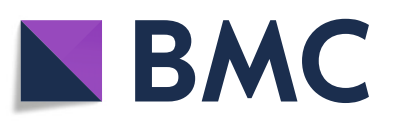

(- The Author(s). 2021 Open Access This article is licensed under a Creative Commons Attribution 4.0 International License, which permits use, sharing, adaptation, distribution and reproduction in any medium or format, as long as you give appropriate credit to the original author(s) and the source, provide a link to the Creative Commons licence, and indicate if changes were made. The images or other third party material in this article are included in the article's Creative Commons licence, unless indicated otherwise in a credit line to the material. If material is not included in the article's Creative Commons licence and your intended use is not permitted by statutory regulation or exceeds the permitted use, you will need to obtain permission directly from the copyright holder. To view a copy of this licence, visit http://creativecommons.org/licenses/by/4.0/ The Creative Commons Public Domain Dedication waiver (http://creativecommons.org/publicdomain/zero/1.0/) applies to the data made available in this article, unless otherwise stated in a credit line to the data. 


\section{Background}

Osteonecrosis of the femoral head $(\mathrm{ONFH})$ is a progressive pathological process that occurs due to multiple factors affecting the blood supply of femoral head [1]. Among the preservation procedures for the treatment of $\mathrm{ONFH}$, intertrochanteric curved varus osteotomy (CVO) is a proximal femoral osteotomy technique that is widely used in Japan [2-12]. It is performed with the aim of removing necrotic regions of the femoral head from the weight-bearing portion, decreasing the load subjected to infarction in order to prevent collapse in the early stage. The key point of CVO is to create a curved varus osteotomy line though the tip of great trochanter and the middle of the lesser trochanter without exceeding the intertrochanteric crest. The osteotomy center is not necessarily located in the femoral head center [13].

Clinically, to estimate the collapse risk after CVO, the intact ratio is used and defined as the intact surface area divided by the weight-bearing area in the femoral head. A post-operative intact ratio of $33.0 \%$ was necessary if a satisfactory result was to be achieved [14], whereas it was prone to collapse if the necrotic lesion was located in the anterolateral weight-bearing portion or with insufficient femoral head coverage [15]. Moreover, the postoperative intact ratio of CVO $<33.3 \%$ and lateral centeredge (LCE) angle $<25^{\circ}$ were identified as independent factors leading to radiographic failure and conversion to total hip arthroplasty from clinical reports [16]. However, from a biomechanical viewpoint, few studies have focused on the stress changes of necrotic bone and the influence of different LCE angles on the stress distribution of necrotic bone after CVO. In addition, the correlation between the intact ratio and stress in the necrotic bone has not been discussed.

A finite element analysis (FEA) is a popular computer simulation for evaluating the stress and strain state in the human body, including studies on ONFH [9, 17-20]. Thus, the purpose of the present study was to evaluate the influence of CVO on the stress in the necrotic femoral head using an FEA. We also evaluated the effect of the LCE angle on the stress distribution in the segment of necrotic bone for better decision-making in relation to CVO.

\section{Methods}

This biomechanical study was approved by our ethical review committee (NO. 0-0672). A healthy volunteer (sex: male, age: 27 years, height: $164 \mathrm{~cm}$, body weight: $66 \mathrm{~kg}$ ) without any musculoskeletal disease or history of hip joint operations was recruited. Quantitative computed tomography (QCT) was scanned in combination with a calibration phantom (B-MAS200, Kyoto-kagaku, Kyoto, Japan). The resolution of each CT image was 512 by 512 pixels with a slice thickness of $1.0 \mathrm{~mm}$, and the pixel size was $0.782 \mathrm{~mm} /$ pixel under $120 \mathrm{KV}$ and 102.50 $\mathrm{mA}$ conditions.

\section{CVO model with ONFH}

The intact hip joint model was constructed from the QCT data by segmenting the bony structure of the ilium and femur using a medical image processing software program (Mimics 22, Materialise, Belgium) (Fig. 1a). The cartilage geometry was created by filling the clearance gap between the acetabulum and the femoral head.

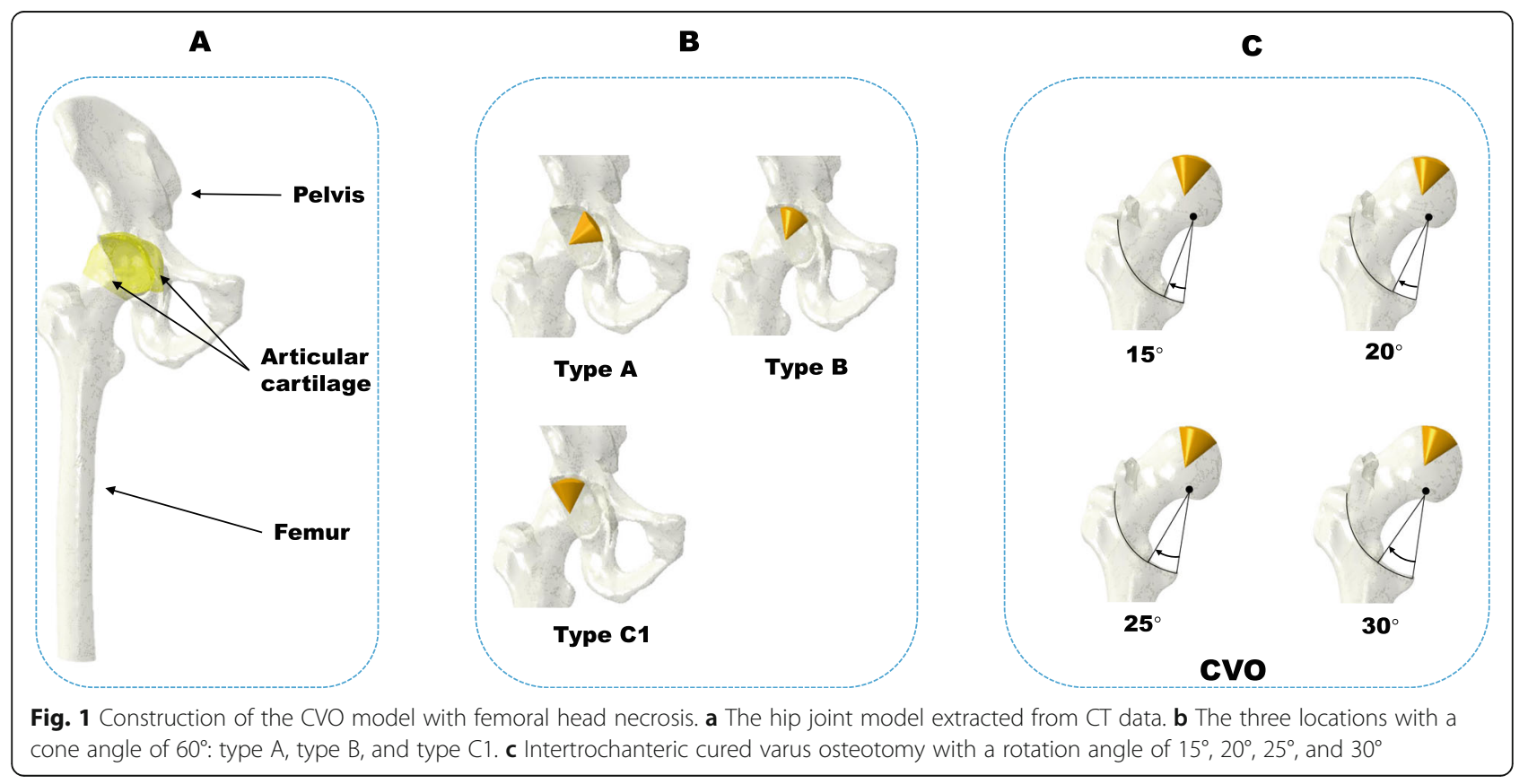


Then, the cartilage model was divided into acetabular and femoral head cartilage with a spherical surface [21].

The necrotic bone model was created based on the Japanese Investigation Committee (JIC) classification [22]. The size of the necrotic lesion was set as a conoid shape (cone angle: $60^{\circ}$ ) to represent an early stage, low risk, and pre-collapse of the lesion [18]. The typical three locations of the necrotic bone (types A, B, C1) were simulated. (Fig. 1b). In brief, the weight-bearing portion of the acetabulum was trisected; the vertical line through lateral node of each aliquot reached the point over the femoral head that was defined as the boundary of the lateral locations of types $\mathrm{A}, \mathrm{B}, \mathrm{C} 1$ in the central coronal section of the femoral head of CT images. The locations matched with the changes of the weightbearing portion, which were decided by different LCE angles in this study.

The CVO models were created using a CAD system (SolidWorks 2016, SolidWorks Corp., USA) (Fig. 1c). The osteotomy plane was set from the frontal view, and the femur model was cut along the plane by Boolean operations. The osteomized proximal part was rotated and fixed to the distal femur with four different angles of $15^{\circ}, 20^{\circ}, 25^{\circ}$, and $30^{\circ}$ without implants.

\section{D Measurement of geometric parameters}

Femoral head coverage area was measured in each hip joint model [23]. The spline curve was fit to the rim of the acetabulum (Fig. 2a, black line, lateral to medial) and projected on the surface of the femoral head to create an area of femoral head coverage (Fig. 2b). The weightbearing area was defined as the lunate surface in this study. The border curve between the lunate surface and the acetabular fossa (Fig. 2a, red line) was projected on the surface of the femoral head to create the weightbearing area (Fig. 2c). The intact area was defined as the area with the necrotic region removed from the weightbearing area (Fig. 2d). The intact ratio was calculated as the intact area/the weight-bearing area. The results of the measurement are summarized in (Table 1).

\section{Material properties assignment and boundary configurations}

The hip joint models were meshed 928,127 four-node tetrahedral elements with an element size of approximately $1 \mathrm{~mm}$ for bone and cartilage, which are assumed to be isotropic and elastic materials. For the femur model, heterogeneous Young's modulus was assigned to each element based on QCT data (Fig. 3a) [24]. Briefly, the parameters used for converting Hounsfield Units $(\mathrm{HU})$ to radiographic $\mathrm{CT}$ density $\left(\rho_{\mathrm{QCT}}\left(\mathrm{g} / \mathrm{cm}^{3}\right)\right.$ (Eq. (1)) were calculated from the B-MAS200 phantom [25] and from $\rho_{Q C T}$ to Ash density $\left(\rho_{a s h}\left(\mathrm{~g} / \mathrm{cm}^{3}\right)\right.$ (Eq. (2)) [26], then the apparent density that was calculated from the Ash density with a ratio of 0.6 [27] was converted to the elastic modulus (Eq. (3)) [28].

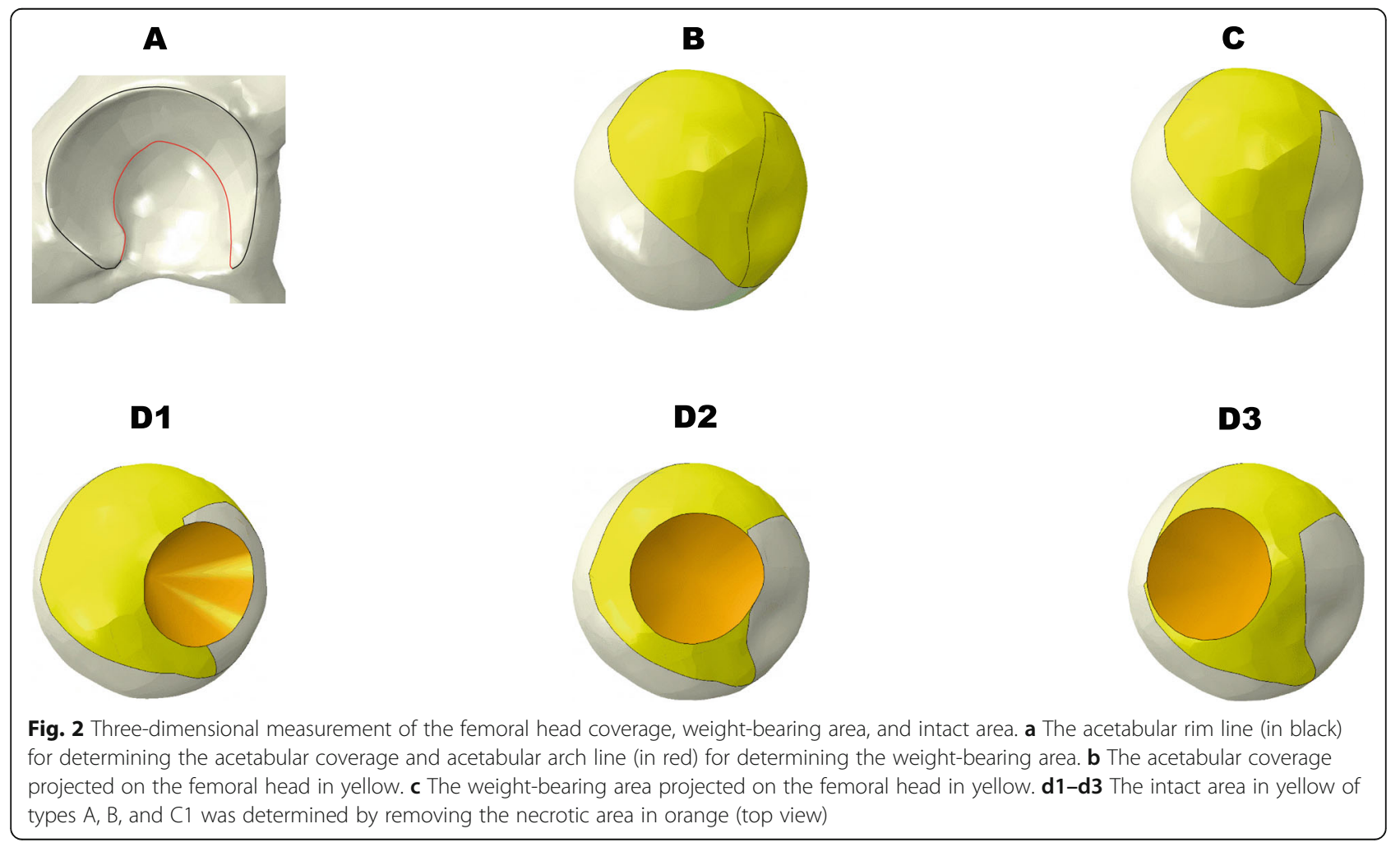


Table 1 3D-Measurement of geometrical parameters

\begin{tabular}{|c|c|c|c|c|c|}
\hline Necrosis & CVO angle & FHC $\left(\mathrm{mm}^{2}\right)$ & WBA $\left(\mathrm{mm}^{2}\right)$ & Intact area $\left(\mathrm{mm}^{2}\right)$ & Intact ratio \\
\hline \multirow[t]{5}{*}{ Type A } & 0 & 2776.06 & 1971.59 & 1795.18 & 0.91 \\
\hline & 15 & 2808.67 & 2001.17 & 1927.44 & 0.96 \\
\hline & 20 & 2816.22 & 1998.32 & 1952.64 & 0.98 \\
\hline & 25 & 2856.75 & 2015.33 & 1993.78 & 0.99 \\
\hline & 30 & 2874.13 & 2018.79 & 1997.84 & 0.99 \\
\hline \multirow[t]{5}{*}{ Type B } & 0 & 2776.06 & 1971.59 & 1502.76 & 0.76 \\
\hline & 15 & 2808.67 & 2001.17 & 1635.54 & 0.82 \\
\hline & 20 & 2816.22 & 1998.32 & 1677.76 & 0.84 \\
\hline & 25 & 2856.75 & 2015.33 & 1749.82 & 0.87 \\
\hline & 30 & 2874.13 & 2018.79 & 1834.20 & 0.91 \\
\hline \multirow[t]{5}{*}{ Type C1 } & 0 & 2776.06 & 1971.59 & 1457.45 & 0.74 \\
\hline & 15 & 2808.67 & 2001.17 & 1497.21 & 0.75 \\
\hline & 20 & 2816.22 & 1998.32 & 1507.74 & 0.75 \\
\hline & 25 & 2856.75 & 2015.33 & 1560.04 & 0.77 \\
\hline & 30 & 2874.13 & 2018.79 & 1597.72 & 0.79 \\
\hline
\end{tabular}

FHC femoral head coverage, WBA weight-bearing area

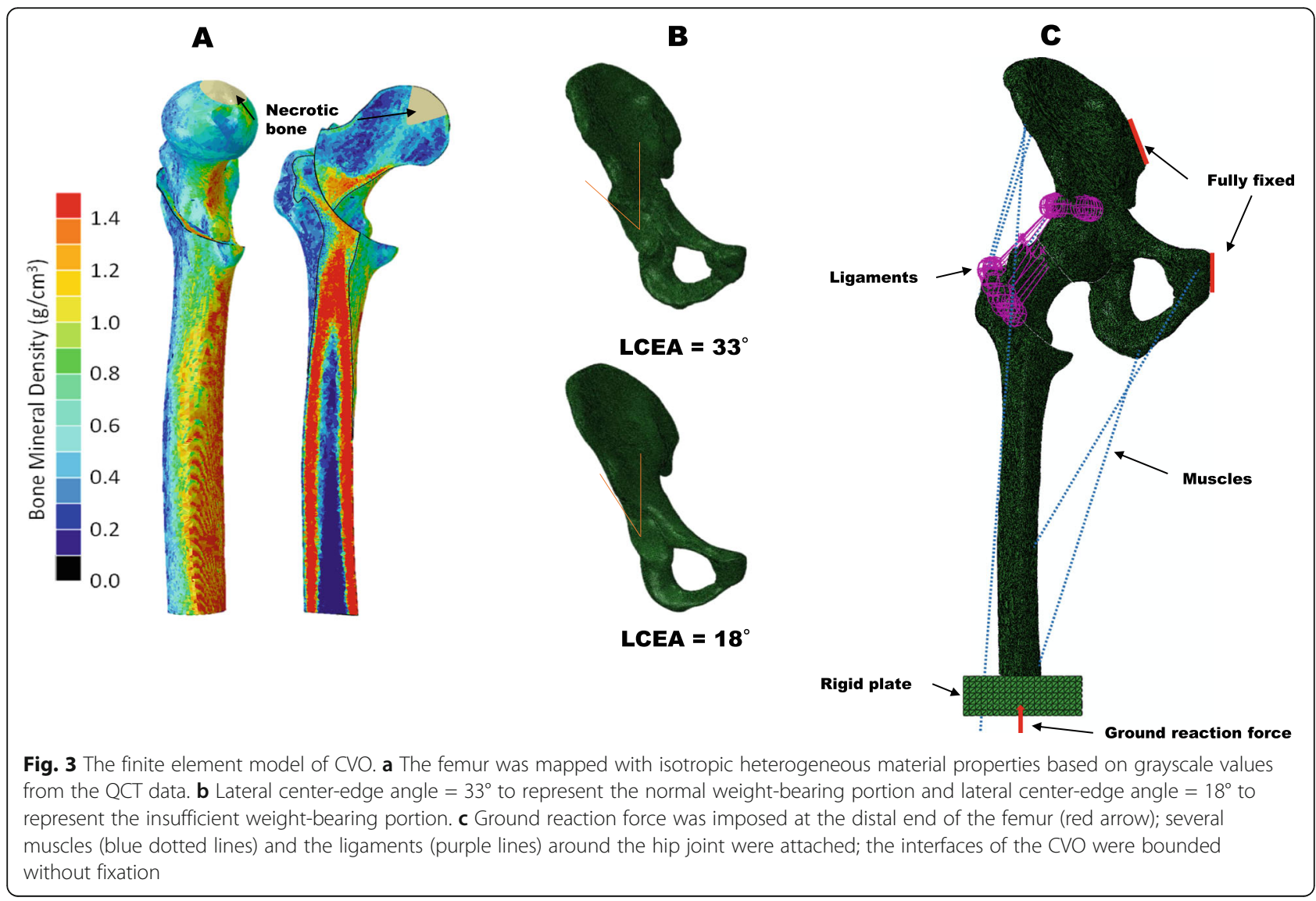




$$
\begin{aligned}
& \rho_{Q C T}\left(\mathrm{~g} / \mathrm{cm}^{3}\right)=0.9863 \mathrm{HU}-2.0804 \\
& \rho_{\text {ash }}\left(\mathrm{g} / \mathrm{cm}^{3}\right)=0.877 \times \rho_{Q C T}+0.0789 \\
& E=6850 \rho_{\text {app }}^{1.49}
\end{aligned}
$$

The necrotic lesion, cartilage and ilium were assigned with homogeneous material properties based on the literature (Table 2) [18, 29, 30].

To simulate the standing loading, a ground reaction force of $700 \mathrm{~N}$ was applied to a rigid plate fixed to the distal end of the femur. Seven muscles around the hip joint were modeled using connector elements based on a previous study (Table 3) [29]. The forces can minimize the bending moment in every cross-section of the femur [31]. The hip capsular ligaments were modeled as a 1D springs element. The stiffness of the superior iliofemoral, inferior iliofemoral, ischiofemoral, and pubofemoral ligaments were set at 96, 102, 40, and $36 \mathrm{~N} / \mathrm{mm}$, respectively. The width of ligament was simulated by several springs; the numbers of springs was adopted from a previous study [32]. The stiffness of each spring was calculated as the stiffness of ligament divided by the number of springs. The position of origin and insertion of springs was determined at the surface nodes of bone and mimicked the anatomical position of the ligament as much as possible [33]. The pubic symphysis and sacroiliac joint were fully fixed to prevent translation and rotation. The osteotomy interface was set as a bond, and the contact area of cartilage was modeled as frictionless.

We also modified the acetabulum shape to investigate the influence of the weight-bearing portion on the stress state in the necrotic lesion after CVO (Fig. 3b). The model with an LCE angle of $33^{\circ}$ represented the normal weight-bearing portion, and the model with an LCE angle of $18^{\circ}$ represented the insufficient portion [34, 35]. Finally, a total of 30 different finite element models were created simulating three locations of necrosis combined with four CVO angles in two different LCE angle conditions (Fig. 3c). The FE analysis was performed using a general-purpose FEA software program (ABAQUS 2019, Dassault Systems, Providence, RI).

Table 2 Material properties for FE model

\begin{tabular}{lll}
\hline Component & Elastic modulus (MPa) & Poisson's ratio \\
\hline Femur bone & $7.173-15769.50$ & 0.3 \\
Pelvis bone & 17000 & 0.3 \\
Necrotic bone & 124.6 & 0.152 \\
Articular cartilage & 10.5 & 0.45 \\
\hline
\end{tabular}

Table 3 Loading for finite element model

\begin{tabular}{llll}
\hline Component & Forces (N) & Component & Forces (N) \\
\hline Adductor longus & 560 & Gluteal minimus & 300 \\
Adductor magnus & 600 & Piriformis & 500 \\
Gluteal maximus & 550 & Tensor fascia latae & 300 \\
Gluteal medius & 700 & Ground reaction force & 700 \\
\hline
\end{tabular}

\section{Sensitivity studies and mesh convergence tests}

Changes in the assumed material properties were performed to investigate how such properties affect the stress and strain predictions for sensitivity studies in physiological conditions using the intact hip joint model. We analyzed the variations in the FE model prediction, when the elastic modulus of the pelvis bone and articular cartilage were changed to $\pm 10 \%$ of the initial values [30]. The results of the sensitivity studies are presented in Table 4. In our selected models, the variation of the sensitivity studies was confirmed to be $<5 \%$ by evaluating the maximum von Mises stress of the femur. This information demonstrated that the alteration in material parameters did not result in significant changes. According to the modulus and Poisson's ratios, the FEpredicted stress was relatively insensitive to change [36]. This indicates that the material coefficient used in the study was stable and effective.

Mesh convergence tests were performed to confirm the discretization for the analysis. A mesh was generally considered to be sufficiently refined when an increase in mesh resolution yielded less than a $5 \%$ change in the result [37]. The number of tetrahedral elements in the intact femur model was increased to analyze the stress variation by evaluating the maximum von Mises stress of the femur (Table 5). Based on the convergence test, the elements of 928,127 with an average element size of $1 \mathrm{~mm}$ (percentage variation within 5\%) was chosen as the final FE model to minimize the discretization error for the verification of the calculation [38].

Table 4 Sensitivity studies of FE models

\begin{tabular}{llll}
\hline Models & Pelvis bone & Cartilage & Max. von Mises stress (MPa) \\
\hline 1 & $E=17 \mathrm{GPa}$ & $E=10.5 \mathrm{MPa}$ & 298.50739 \\
$V$ & $=0.3$ & $V=0.45$ & \\
2 & $E=17 \mathrm{GPa}$ & $E=11.55 \mathrm{MPa}$ & 298.50583 \\
& $V=0.3$ & $V=0.45$ & \\
3 & $E=17 \mathrm{GPa}$ & $E=9.45 \mathrm{MPa}$ & 298.50977 \\
& $V=0.3$ & $V=0.45$ & \\
4 & $E=18.7 \mathrm{GPa}$ & $E=10.5 \mathrm{MPa}$ & 298.50909 \\
& $V$ & $V=0.45$ & \\
5 & $E=15.3 \mathrm{GPa}$ & $E=10.5 \mathrm{MPa}$ & 298.50528 \\
& $V=0.3$ & $V=0.45$ & \\
\hline
\end{tabular}

$E$ elastic modulus, $v$ Poisson's ratio 
Table 5 Convergence tests of FE models

\begin{tabular}{lll}
\hline Models & Elements no. & Max. von Mises stress (MPa) \\
\hline 1 & 516060 & 298.50555 \\
2 & 553764 & 298.50919 \\
3 & 585758 & 298.50858 \\
4 & 759401 & 298.50708 \\
5 & 928127 & 298.50739 \\
6 & 993256 & 298.50757 \\
\hline
\end{tabular}

\section{Results}

The effectiveness of CVO on stress reduction in necrotic bone

The maximum and mean von Mises stress in the necrotic bone were reduced with an increase in the CVO angle (Fig. 4). In particular, in the insufficient weightbearing models (LCE angle of $18^{\circ}$ ), the maximum stress was reduced from 15.67 to $6.13 \mathrm{MPa}$ for type $\mathrm{C} 1$ and from 13.73 to $3.76 \mathrm{MPa}$ for type B (Fig. 4a). Correspondingly, the stress concentration at the interface of healthy and necrotic bone was weakened, accompanied by an increase in the CVO angle (Figs. 5 and 6). For type A, with both LCE angles, slight stress reduction was observed after CVO in comparison to types B and C1 (Fig. 4b, d).

\section{Influence of the weight-bearing portion}

The LCE angles affected the maximum and mean stress in the necrotic bone, with the exception of type A. The stress with an LCE angle of $18^{\circ}$ were higher in comparison to the stress with an LCE angle of $33^{\circ}$, for types B (maximum stress: 13.73 vs $6.83 \mathrm{MPa}$ ) and $\mathrm{C} 1$ (maximum stress: 15.67 vs $8.14 \mathrm{MPa}$ ) in CVO $0^{\circ}$ models (Fig. 4a). With an LCE angle of $18^{\circ}$, extensive stress distribution was observed in the necrotic region in comparison to an LCE angle of $33^{\circ}$ (Figs. 5 and 6).

\section{Relationship between geometric measurements and stress of necrosis}

The correlation of these geometric measurements with the mean von Mises stress of the necrotic region was compared (Fig. 7). From the results of this linear regression analysis, the geometric measurements and stress had a negative relationship with good fitness, as determined by the $R^{2}$ value. The stress of necrosis decreased by increasing the intact ratio, intact area, weight-bearing area, and femoral head coverage. However, the intact ratio had more influence on the stress of the necrotic bone in comparison to other geometric measurements with a large slope value.

\section{Discussion}

Proximal femoral osteotomy for the treatment of ONFH is performed with the aim of eliminating the mechanical factors suffered by necrotic bone. This is why the mechanical simulation of such procedures is necessary for assisting preoperative decision-making [9]. In this study, the biomechanical effectiveness of CVO was addressed by evaluating the stress of necrotic bone after CVO (Fig. 4). All types of necrotic lesions would mechanically benefit from CVO with different levels of stress reduction. As expected, in the case of types B and C1, the higher degree of $\mathrm{CVO}$ performed, the greater the degree of stress reduction that was achieved, because the necrotic bone is removed from the weight-bearing portion to a medial site by varus osteotomy. For example, the maximum stress of type $\mathrm{C} 1$ from $8.14 \mathrm{MPa}$ in $0^{\circ}$


Fig. 4 Von Mises stress in different models. a Maximum von Mises stress of the models. b The maximum von Mises stress reduction after CVO. c The mean von Mises stress of the models. $\mathbf{d}$ The mean von Mises stress reduction after CVO 

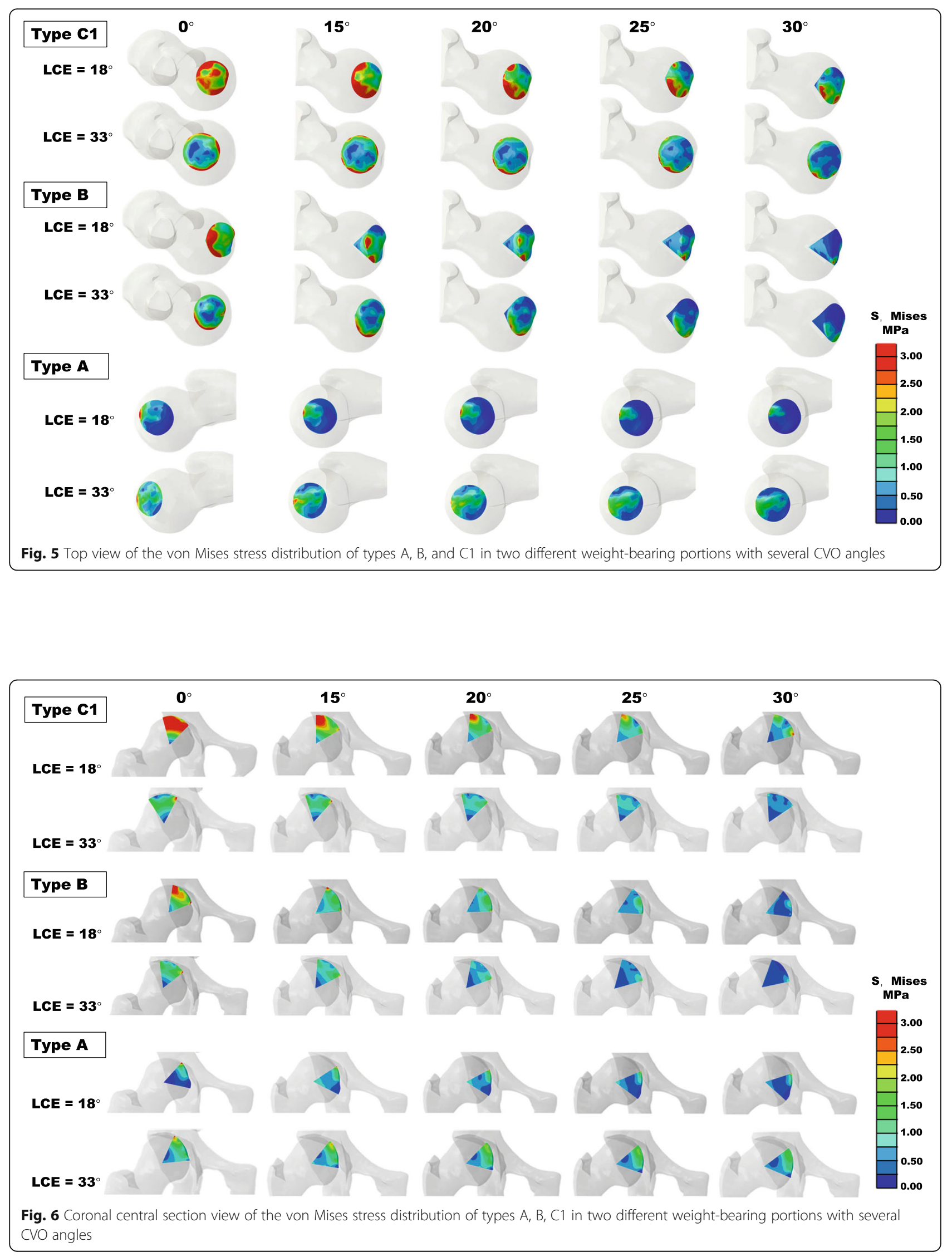


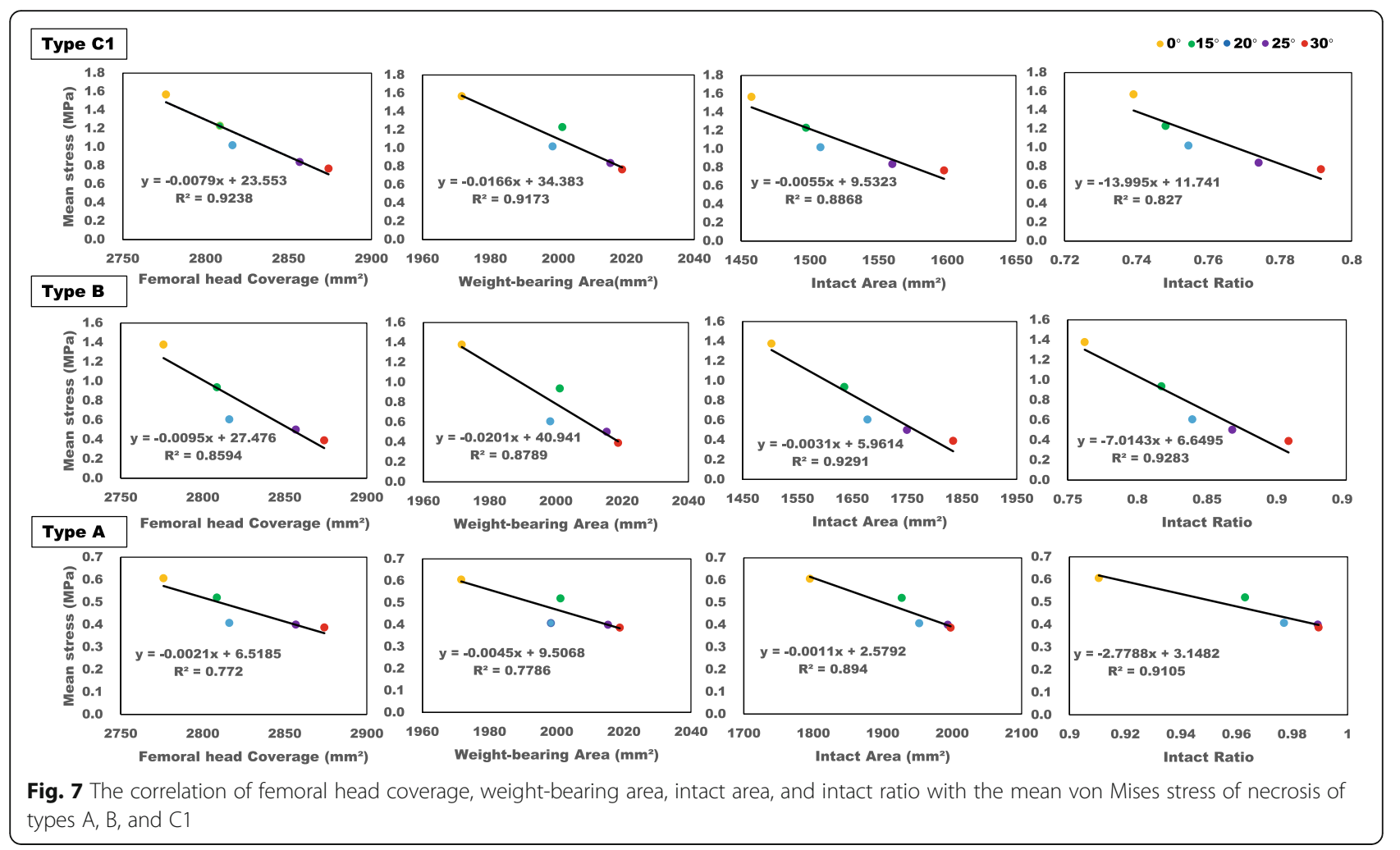

situation was reduced to $4.53 \mathrm{MPa}$ after a CVO of $30^{\circ}$ with a maximum stress reduction of $44.3 \%$ (Fig. $4 \mathrm{a}$, b). These results suggested that $\mathrm{CVO}$ was an effective way to reduce the stress level in necrotic bone.

Our simulation demonstrated that the appropriate $\mathrm{CVO}$ angle depended on the type of necrotic lesion. For type A, there was little change in the stress after CVO, and the stress level was relatively lower in $0^{\circ}$ models. This result can support the clinical repots $[7,14,16,39-$ 44]. Therefore, it was not effective to perform the CVO with type A. For type B, satisfactory results could be achieved from $20^{\circ}(0.61 \mathrm{MPa})$, and for type $\mathrm{C} 1$, an angle of at least $30^{\circ}(0.77 \mathrm{MPa})$ was considered safe, if the stress level of type A (0.61 MPa) was regarded as a standard, based on the results predicted in this study.

Unfavorable biomechanical situation of the hip such as acetabular dysplasia, which can increase contact stress as well as has been identified as a risk factor for the collapse of necrotic bone, leads to highly nonuniform contact stress distribution in comparison to the normal hip joint [16]. In this study, the stress in the insufficient weight-bearing portion models was higher in comparison to normal weight-bearing models. In the case of type $\mathrm{C} 1$, the mean stress value was $2.85 \mathrm{MPa}$ of LCE angle $18^{\circ}$ vs. $1.57 \mathrm{MPa}$ of LCE angle $33^{\circ}$ in the no osteotomy model, and it was higher $(0.90 \mathrm{MPa}$ vs $0.77 \mathrm{MPa})$ in the LCE angle $18^{\circ}$ model even after CVO $30^{\circ}$. Type A had received the least influence from the weight-bearing portion (Fig. 4c). From these results, the influence of the weight-bearing portion on stress distribution of lesion was location-dependent, the more lateral site located, the more stress suffered. Thus, further procedures, such as periacetabular osteotomy, should be considered, when $\mathrm{CVO}$ is performed for a hip with an unfavorable biomechanical situation.

Stress concentrations were observed at not only the lateral interface region but also anterior region for types $\mathrm{B}$ and $\mathrm{C} 1$ (Figs. 5 and 6), which indicated that the anterior side was also at risk of collapse. The finding was supported by a clinical report on CVO [39]. This report suggested that the anterior necrotic angle was associated with the progressive collapse of the anterior lesion.

The intact ratio is used as the most important indicator for evaluating the risk of collapse after $\mathrm{CVO}$ in the clinical setting [14]. It is calculated from the transposed intact articular surface of the femoral head and the weight-bearing area of the acetabulum on anteroposterior radiographs [39]. However, the relationship between the intact ratio measured in $3 \mathrm{D}$ and the stress of necrotic bone after CVO was firstly discussed in this study. We found that a strong negative correction between the intact ratio and the stress level of necrotic bone after $\mathrm{CVO}$ had more influence on stress distribution with a larger slope value in the linear regression model, in comparison to the other parameters of femoral head coverage, weight-bearing area, and intact area (Fig. 7). Thus, it 
was confirmed that the intact ratio could be a bridge between the clinical results and the stress reduction of necrosis after CVO.

The present study was associated with some limitations. (1) Only one healthy subject was evaluated; thus, the deviation derived from patient-specific differences could not be considered $[45,46]$. The study should have investigated additional types of necrosis from patient data. (2) Finite element models of physiological loading conditions should generally be validated from electromyography data [4749]. For the present study, validation of the predicted results depended on similarity to the physical phenomenon of the real structure of femoral head with an intact model subjected to loading. (3) The interfaces of the CVO were assumed to be fully bonded, which more likely simulates the healed stage after $\mathrm{CVO}$ without taking the influence of the fixation device into account when simulating the initial postoperative stage. (4) The mechanical property of human articular cartilage displayed a viscoelastic and nonlinear mechanical response to loading $[46,50]$; however, an isotropic homogeneous material property was assigned in the study [29, 35]. (5) This simulation only addressed mechanical factors that would affect the stress distribution of necrotic bone; however, biological reaction that may be different after each $\mathrm{CVO}$ also needs to be considered.

\section{Conclusions}

Understanding the complicated interdependence of the size and location of necrotic lesions and the configuration of the hip and pelvis is important in making decisions regarding optimal treatment. This finite element study suggested all types of lesions would mechanically benefit from CVO. However, for type $\mathrm{B}$, an angle of $>20^{\circ}$ was recommended, and for type $\mathrm{C} 1$, an angle of at least $30^{\circ}$ was safe, decreasing to the stress level of type A. An insufficient weight-bearing portion at acetabulum such as dysplasia can lead to the stress concentration at the necrotic bone rather than the normal hip joint. The intact ratio could be a bridge between the clinical outcomes and stress level in CVO.

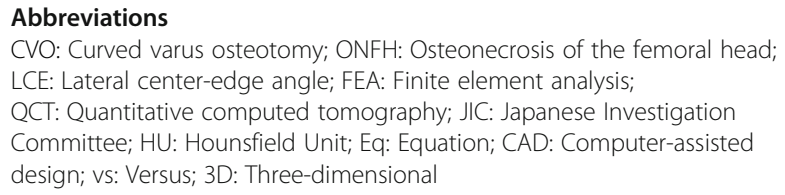

\section{Acknowledgements}

I would like to thank Kenshin Matsue for using his valuable time to check the results. I would also like to thank the Kyoto-kagaku company for providing the calibration phantom (B-MAS200) for the subject-specific bone mineral density measurement.

\section{Authors' contributions}

YW, GY, YN, and EC designed the study and collected the materials and data. YW, TO, and GY conducted the finite element simulation. YW and GY played a major role in writing the manuscript. HA, YN, and EC developed the research question and guided the study. The authors read and approved the final manuscript before submission.

\section{Funding}

This work was supported by JSPS KAKENHI Grant Number JP17K01362. The funder had no role in design of the study, the collection, analysis, and interpretation of the data, or in writing the manuscript.

Availability of data and materials

The data and materials are available from the corresponding author.

\section{Declarations}

Ethics approval and consent to participate

The study was approved by the Ethical Review Committee of Miyazaki University (NO. 0-0672), and informed consent was obtained from subjects.

\section{Consent for publication}

Not applicable

\section{Competing interests}

The authors declare that they have no competing interest.

\section{Author details}

${ }^{1}$ Department of Orthopaedic Surgery, Faculty of Medicine, University of Miyazaki, Miyazaki, Miyazaki, Japan. 'Department of Mechanical Engineering, Faculty of Engineering, University of Miyazaki, Miyazaki, Miyazaki, Japan. ${ }^{3}$ Graduate school of Engineering, University of Miyazaki, Miyazaki, Miyazaki, Japan.

Received: 1 April 2021 Accepted: 13 July 2021

Published online: 23 July 2021

\section{References}

1. Moya-Angeler J, Gianakos AL, Villa JC, Ni A, Lane JM. Current concepts on osteonecrosis of the femoral head. World J Orthop. 2015;6(8):590-601. https://doi.org/10.5312/wjo.v6.i8.590.

2. Mont MA, Carbone JJ, Fairbank AC. Core decompression versus nonoperative management for osteonecrosis of the hip. Clin Orthop Relat Res. 1996;324:169-78. https://doi.org/10.1097/00003086-199603000-00020.

3. Veillette $\mathrm{CJH}$, Mehdian $\mathrm{H}$, Schemitsch EH, Mckee MD. Survivorship analysis and radiographic outcome following tantalum rod insertion for osteonecrosis of the femoral head. J Bone Joint Surg Am. 2006;88:48-55.

4. Keizer SB, Kock NB, Dijkstra PDS, Taminiau AHM, Nelissen RGHH. Treatment of avascular necrosis of the hip by a non-vascularised cortical graft. J Bone Joint Surg Br. 2006;88(4):460-6.

5. Chen WP, Tai $\mathrm{CL}$, Shih $\mathrm{CH}$, Hsieh $\mathrm{PH}$, Leou MC, Lee MS. selection of fixation devices in proximal femur rotational osteotomy: clinical complications and finite element analysis. Clin Biomech. 2004;19(3):255-62. https://doi.org/10.1 016/j.clinbiomech.2003.12.003.

6. Lee YK, Park CH, Ha YC, Kim DY, Lyu SH, Koo KH. Comparison of surgical parameters and results between curved varus osteotomy and rotational osteotomy for osteonecrosis of the femoral head. Clin Orthop Surg. 2017; 9(2):160-8. https://doi.org/10.4055/cios.2017.9.2.160.

7. Sakano S, Hasegawa Y, Torii Y, Kawasaki M, Ishiguro N. Curved intertrochanteric varus osteotomy for osteonecrosis of the femoral head. J Bone Joint Surg Br. 2004;86(3):359-65.

8. Nozawa M, Enomoto F, Shitoto K, Matsuda K, Maezawa K, Kurosawa H. Rotational acetabular osteotomy for osteonecrosis with collapse of the femoral head in young patients. J Bone Joint Surg. 2005;87(3):514-20. https://doi.org/10.2106/00004623-200503000-00006.

9. Baker KJ, Brown TD, Brand RA. A finite-element analysis of the effects of intertrochanteric osteotomy on stresses in femoral head osteonecrosis. Clin Orthop Relat Res. 1989;249:183-98.

10. Quaranta M, Miranda L, Oliva F, Aletto C, Maffulli N. Osteotomies for avascular necrosis of the femoral head. Br Med Bull. 2021;137(1):98-111. https://doi.org/10.1093/bmb/ldaa044.

11. Migliorini F, Maffulli N, Eschweiler J, Tingart M, Baroncini A. Core decompression isolated or combined with bone marrow-derived cell therapies for femoral head osteonecrosis. Expert Opin Biol Ther. 2021;21(3): 423-30. https://doi.org/10.1080/14712598.2021.1862790.

12. Sadile F, Bernasconi A, Russo S, Maffulli N. Core decompression versus other joint preserving treatments for osteonecrosis of the femoral head: a metaanalysis. Br Med Bull. 2016;118(1):33-49. https://doi.org/10.1093/bmb/ldw010. 
13. Nishio A, Sugioka Y. A new technique of the varus osteotomy at the upper end of the femur. Orthop Trauma. 1971;20(3):381-6. https://doi.org/10.5035/ nishiseisai.20.381.

14. Zhao G, Yamamoto T, Ikemura S, Motomura G, Mawatari T, Nakashima Y, et al. Radiological outcome analysis of transtrochanteric curved varus osteotomy for osteonecrosis of the femoral head at a mean follow-up of 12 . 4 years. J Bone Joint Surg Br. 2010;92(6):781-6.

15. Roush TF, Olson SA, Pietrobon R, Braga L, Urbaniak JR. Influence of acetabular coverage on hip survival after free vascularized fibular grafting for femoral head osteonecrosis. J Bone Joint Surg Am. 2006;88(10):2152-8. https://doi.org/10.2106/JBJS.E.00469.

16. Okura T, Hasegawa $Y$, Morita D, Osawa $Y$, Ishiguro N. What factors predict the failure of curved intertrochanteric varus osteotomy for the osteonecrosis of the femoral head? Arch Orthop Trauma Surg. 2016;136(12):1647-55. https://doi.org/10.1007/s00402-016-2563-0.

17. Brown TD, Mutschler TA, Ferguson AB. A non-linear finite element analysis of some early collapse processes in femoral head osteonecrosis. J Biomech. 1982;15(9):705-15. https://doi.org/10.1016/0021-9290(82)90024-0.

18. Lee MS, Tai CL, Senan V, Shih CH, Lo SW, Chen WP. The effect of necrotic lesion size and rotational degree on the stress reduction in transtrochanteric rotational osteotomy for femoral head osteonecrosis - a three-dimensional finite-element simulation. Clin Biomech. 2006;21(9):96976. https://doi.org/10.1016/j.clinbiomech.2006.05.005.

19. Li T, Huang Z, Li Y, Xue Z, Sun J, Gao H, et al. Prediction of collapse using patient-specific finite element analysis of osteonecrosis of the femoral head. Orthop Surg. 2019;11(5):794-800. https://doi.org/10.1111/os.12520.

20. Yang JW, Koo KH, Lee MC, Yang P. D.Noh M, Kim SY, Kim K, Ha YC, Joun MS. Mechanics of femoral head osteonecrosis using three-dimensional finite element method. Arch Orthop Trauma Surg. 2002;122(2):88-92. https://doi. org/10.1007/s004020100324.

21. Henak CR, Carruth ED, Anderson AE, Harris MD, Ellis BJ, Peters CL, et al. Finite element predictions of cartilage contact mechanics in hips with retroverted acetabula. Osteoarthr Cartil. 2013;21(10):1522-9. https://doi.org/1 0.1016/j.joca.2013.06.008.

22. Sugano N, Atsumi T, Ohzono K, Kubo T, Hotokebuchi T, Takaoka K. The 2001 revised criteria for diagnosis, classification, and staging of idiopathic osteonecrosis of the femoral head. J Orthop Sci. 2002;7(5):601-5. https://doi. org/10.1007/s007760200108.

23. Hansen BJ, Harris MD, Anderson LA, Peters CL, Weiss JA, Anderson AE. Correlation between radiographic measures of acetabular morphology with $3 \mathrm{D}$ femoral head coverage in patients with acetabular retroversion. Acta Orthop. 2012;83(3):233-9. https://doi.org/10.3109/17453674.2012.684138.

24. Tanaka H, Yamako G, Kurishima H, Yamashita S, Mori Y, Chiba D, et al. Biomechanical analysis of supra-acetabular insufficiency fracture using finite element analysis. J Orthop Sci. 2018;23(5):825-33. https://doi.org/10.1016/j. jos.2018.04.005.

25. Knowles NK, Reeves JM, Ferreira LM. Quantitative Computed Tomography $(\mathrm{QCT})$ derived Bone Mineral Density (BMD) in finite element studies: a review of the literature. J Exp Orthop. 2016:3(1):36. https://doi.org/10.1186/ s40634-016-0072-2

26. Schileo E, Dall'ara E, Taddei F, Malandrino A, Schotkamp T, Baleani M, et al. An accurate estimation of bone density improves the accuracy of subjectspecific finite element models. J Biomech. 2008:41(11):2483-91. https://doi. org/10.1016/j.jbiomech.2008.05.017.

27. Ali AA, Cristofolini L, Schileo E, Hu H, Taddei F, Kim RH, et al. Specimenspecific modeling of hip fracture pattern and repair. J Biomech. 2014;47(2): 536-43. https://doi.org/10.1016/j.jbiomech.2013.10.033.

28. Morgan EF, Bayraktar HH, Keaveny TM. Trabecular bone modulus-density relationships depend on anatomic site. J Biomech. 2003;36(7):897-904 https://doi.org/10.1016/S0021-9290(03)00071-X.

29. Zhou GQ, Pang ZH, Chen QQ, He W, Chen ZQ, Chen LL, et al. Reconstruction of the biomechanical transfer path of femoral head necrosis: a subject-specific finite element investigation. Comput Biol Med. 2014;52: 96-101. https://doi.org/10.1016/j.compbiomed.2014.04.002.

30. Ravera EP, Crespo MJ, Guarnieri FA, Braidot AA. Stress in human pelvis throughout the gait cycle: development, evaluation and sensitivity studies of a finite element model. IFMBE Proceeding. 2015;49:246-9. https://doi. org/10.1007/978-3-319-13117-7_64.

31. Sverdlova NS, Witzel U. Principles of determination and verification of muscle forces in the human musculoskeletal system: muscle forces to minimise bending stress. J Biomech. 2010;43(3):387-96. https://doi.org/10.1 016/j.jbiomech.2009.09.049.

32. Zou Z, Chávez-Arreola A, Mandal P, Board TN, Alonso-Rasgado T. Optimization of the position of the acetabulum in a ganz periacetabular osteotomy by finite element analysis. J Orthop Res. 2013;31(3):472-9. https://doi.org/10.1002/jor.22245.

33. Hewitt J, Guilak F, Glisson R, Vail TP. Regional material properties of the human hip joint capsule ligaments. J Orthop Res. 2001;19(3):359-64. https:// doi.org/10.1016/S0736-0266(00)00035-8.

34. Wylie JD, Kapron AL, Peters CL, Aoki SK, Maak TG. Relationship between the lateral center-edge angle and 3-dimensional acetabular coverage. Orthop J Sport Med. 2017:5(4):2325967117700589.

35. Zhao X, Chosa E, Totoribe K, Deng G. Effect of periacetabular osteotomy for acetabular dysplasia clarified by three-dimensional finite element analysis. J Orthop Sci. 2010;15(5):632-40. https://doi.org/10.1007/s00776-010-1511-z.

36. Anderson AE, Peters $C L$, Tuttle BD, Weiss JA. Subject-specific finite element model of the pelvis: development, validation and sensitivity studies. J Biomech Eng. 2005;127(3):364-73. https://doi.org/10.1115/1.1894148.

37. Anderson AE, Ellis BJ, Weiss JA. Verification, validation and sensitivity studies in computational biomechanics. Comput Methods Biomech Biomed Engin. 2007;10(3):171-84. https://doi.org/10.1080/10255840601160484.

38. Oreskes N, Shrader-Frechette K, Belitz K. Verification, validation, and confirmation of numerical models in the earth sciences. Science. 1994; 263(5147):641-6. https://doi.org/10.1126/science.263.5147.641.

39. Kubo Y, Motomura G, Ikemura S, Hatanaka H, Utsunomiya T, Hamai S, et al. Effects of anterior boundary of the necrotic lesion on the progressive collapse after varus osteotomy for osteonecrosis of the femoral head. J Orthop Sci. 2020;25(10):145-51. https://doi.org/10.1016/j.jos.2019.02.014.

40. Shi L, Fan Y, Zhang C, Shen J. Value of virtual reality technology in preoperative planning of transtrochanteric curved varus osteotomy for avascular necrosis of femoral head in adults. Zhongguo Xiu Fu Chong Jian Wai Ke Za Zhi. 2019;33(8):923-8. https://doi.org/10.7507/1002-1892.201903083.

41. Osawa Y, Seki T, Okura T, Takegami Y, Ishiguro N, Hasegawa Y. Curved intertrochanteric varus osteotomy vs total hip arthroplasty for osteonecrosis of the femoral head in patients under 50 years old. J Arthroplasty. 2020; 35(6):1600-5. https://doi.org/10.1016/j.arth.2020.01.026.

42. Takegami Y, Komatsu D, Seki T, Ishiguro N, Hasegawa Y. Total hip arthroplasty after failed curved intertrochanteric varus osteotomy for avascular necrosis of the femoral head. Nagoya J Med Sci. 2016;78(1):89-97.

43. Ikemura S, Yamamoto T, Jingushi S, Nakashima Y, Mawatari T, Iwamoto Y. Leg-length discrepancy after transtrochanteric curved varus osteotomy for osteonecrosis of the femoral head. J Bone Joint Surg Br. 2007;89(6):725-9.

44. Hamanishi M, Yasunaga Y, Yamasaki T, Mori R, Shoji T, Ochi M. The clinical and radiographic results of intertrochanteric curved varus osteotomy for idiopathic osteonecrosis of the femoral head. Arch Orthop Trauma Surg. 2014;134(3):305-10. https://doi.org/10.1007/s00402-013-1919-y.

45. Shi J, Chen J, Wu J, Chen F, Huang G, Wang Z, et al. Evaluation of the 3D finite element method using a tantalum rod for osteonecrosis of the femoral head. Med Sci Monit. 2014;20:2556-64. https://doi.org/10.12659/MSM.890920.

46. Bae JY, Kwak DS, Park KS, Jeon I. Finite element analysis of the multiple drilling technique for early osteonecrosis of the femoral head. Ann Biomed Eng. 2013;41(12):2528-37. https://doi.org/10.1007/s10439-013-0851-1.

47. Kaze AD, Maas S, Arnoux PJ, Wolf C, Pape D. A finite element model of the lower limb during stance phase of gait cycle including the muscle forces. BioMed Eng OnLine. 2017;16(1):138. https://doi.org/10.1186/s12938-017-0428-6.

48. Seo JW, Kang DW, Kim JY, Yang ST, Kim DH, Choi JS, et al. Finite element analysis of the femur during stance phase of gait based on musculoskeletal model simulation. Biomed Mater Eng. 2014;24(6):2485-93. https://doi.org/1 0.3233/BME-141062.

49. Hicks JL, Uchida TK, Seth A, Rajagopal A, Delp SL. Is my model good enough? Best practices for verification and validation of musculoskeletal models and simulations of movement. J Biomech Eng. 2015;137(2):020905. https://doi.org/10.1115/1.4029304.

50. Robinson DL, Kersh ME, Walsh NC, Ackland DC, de Steiger RN, Pandy MG. Mechanical properties of normal and osteoarthritic human articular cartilage. J Mech Behav Biomed Mater. 2016;61:96-109. https://doi.org/10.1 016/j.jmbbm.2016.01.015

\section{Publisher's Note}

Springer Nature remains neutral with regard to jurisdictional claims in published maps and institutional affiliations. 